\title{
Differential Distributions of Myopia Severity in Younger and Older Individuals with Rhegmatogenous Retinal Detachment
}

\author{
Elvioza Elviozal,2 \\ Denny Agustiningsih ${ }^{3}$ \\ Suhardjo Prawiroranu ${ }^{2}$ \\ Muhammad Bayu Sasongko (D) ${ }^{2}$ \\ IJEC Eye Hospitals \& Clinics, Jakarta, \\ Indonesia; ${ }^{2}$ Department of \\ Ophthalmology, Faculty of Medicine, \\ Public Health, and Nursing, Universitas \\ Gadjah Mada - Sardjito Eye Center, \\ Dr. Sardjito General Hospital, Yogyakarta, \\ Indonesia; ${ }^{3}$ Department of Physiology, \\ Faculty of Medicine, Public Health, and \\ Nursing, Universitas Gadjah Mada, \\ Yogyakarta, Indonesia
}

Correspondence: Muhammad Bayu Sasongko

Department of Ophthalmology, Faculty of Medicine Public Health and Nursing, Universitas Gadjah Mada - Sardjito Eye Center, Dr. Sardjito General Hospital, Jalan Farmako Sekip Utara, Yogyakarta, Indonesia

$\mathrm{Tel} / \mathrm{Fax}+62274552850$

Email mb.sasongko@ugm.ac.id

\section{Background}

A recently published observation from the Netherlands showed an interesting incidence of rhegmatogenous retinal detachment (RRD) which mimicked the increasing prevalence of myopia. ${ }^{1}$ This raised a further question whether it is conceivable to link between those two - increasing myopia causing increasing RRD - since individual data on severity of myopia and incident RRD are still lacking. ${ }^{2}$ In line with this, we aimed to report the differential distribution of the severity of myopia in younger and older individuals with RRD.

\section{Materials and Methods}

This was a retrospective study reviewing medical records of all RRD cases attending and undergoing surgery at two major vitreo-retinal (VR) services (Jakarta Eye Hospitals and Clinics and Dr. Cipto Mangunkusumo National General Hospital) in Jakarta, the capital city of Indonesia, between January to December 2016. This study followed the tenets of the Declaration of Helsinki and had been approved by the Medical and Health Research Ethics Committee, Universitas Gadjah Mada. We included cases with ICD-10 diagnosis code of RRD (H 33.0) and at least 18 years of age. We excluded cases with clinical presentation of combined-mechanism retinal detachment (e.g., both tractional and rhegmatogenous $\mathrm{RD}$ ), prior complicated cataract or refractive surgery in the fellow eye.

All information from the eligible medical records was retrieved. We ensured that all eligible cases had received posterior segment examination by a VR consultant using a $78 \mathrm{D}$ condensing lens, three-mirror lens, and binocular indirect ophthalmoscope for both affected and fellow eye. Clinical diagnosis of RRD was confirmed by the presence of retinal detachment associated with retinal break. Myopia severity was determined by glasses prescription of the affected eye, refractive status of the fellow eye and further matched with the a-scan axial length of both eyes. We further categorized myopia severity as no myopia ( $<-0.50 \mathrm{D})$, low myopia $(-0.50$ to $-3.00 \mathrm{D})$, moderate myopia $(-3.0$ to $-6.00 \mathrm{D})$, and high myopia $(\geq-6.0 \mathrm{D})$. Our main analysis was distribution of myopia severity by age group using mean age as a cut-off: young adult $(<48$ years of age) and older adult ( $\geq 48$ years of age). 


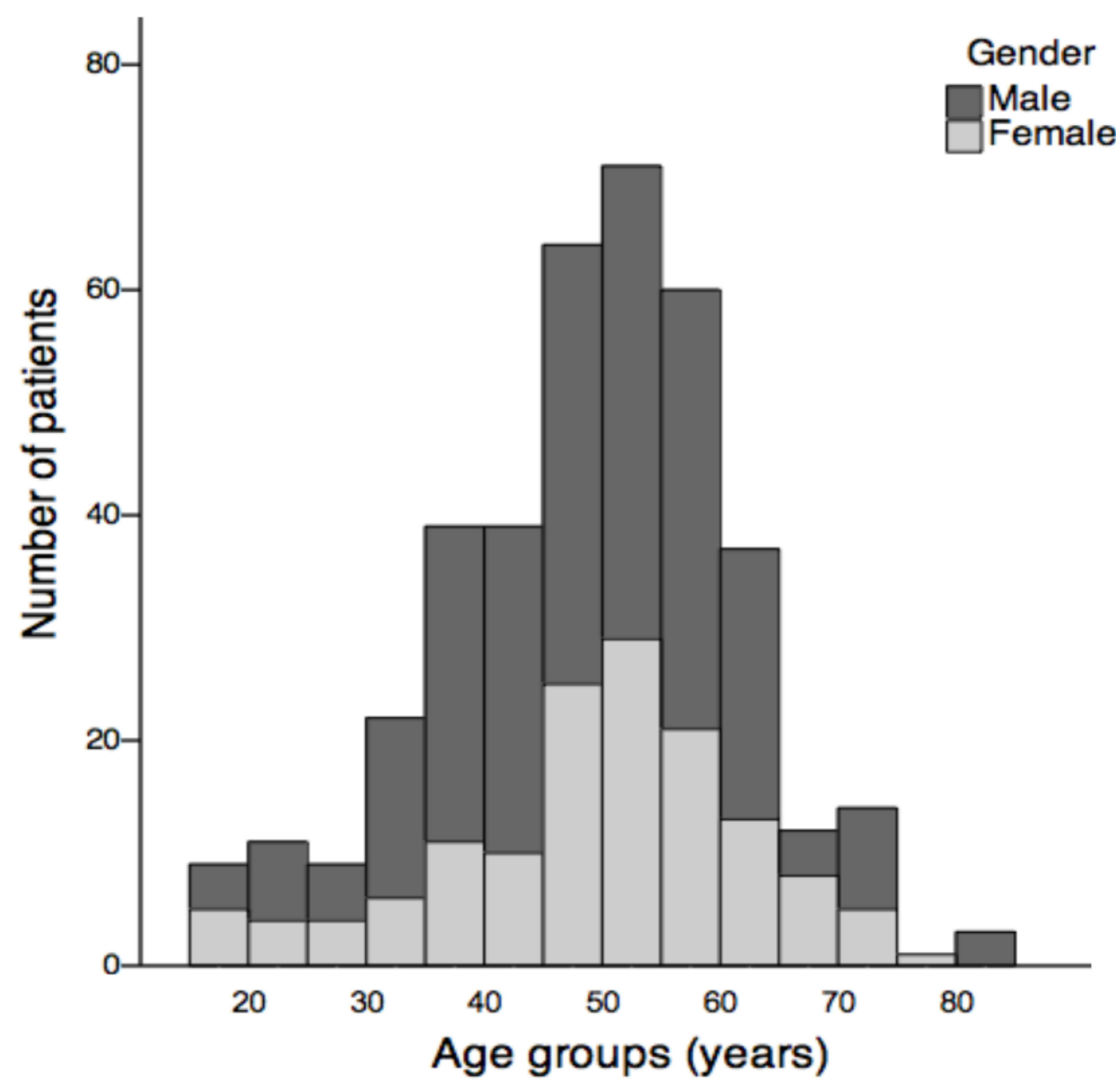

Figure I Age distribution of male and female patients.

\section{Results}

There were 391 patients included in the final analysis (193 [49.4\%] younger and 198 [50.6\%] older group). Mean age of participants was 48.4 years and more than $60 \%$ of the participants were male (63.7\%). Figure 1 shows the distribution of our participants by age group. The incidence of RRD peaked between 45 to 60 years old and the shape of distribution was identical between male and female. Older group had higher proportion of pseudophakia than younger group $(29 \%$ vs $19 \%$; $\mathrm{P}=0.02)$, however both groups had similar proportion of history of ocular trauma and family history of RRD (Supplementary Table).

There was significant difference in myopia severity in younger compared with older age group. Younger adults were significantly more myopic than older adults $(-6.38$ D vs -3.87 D; P <0.01) (Supplementary Table). In addition, Figure 2 shows that the proportion of high myopia was significantly greater in younger group compared with older group (40.4\% vs $13.6 \%$; $\mathrm{P}<0.01)$. Conversely, the proportion of no $(21.1 \%)$ and low myopia $(23.3 \%)$ in younger group were significantly less than older group (40.4 and $34.3 \%$, respectively). After exclusion of pseudophakic individuals, this pattern remained very similar (Figure 2).

\section{Discussion}

Our study showed that the proportion of high myopia in younger individuals with RRD was significantly greater than in older individuals even after exclusion of pseudophakic individuals. Findings from this study were very consistent with a previous study by Kim and associates from a Korean population showing that the majority of younger individuals with RRD had high myopia compared with older individuals, determined by axial length of $>26 \mathrm{~mm}^{3}$

Myopia has been strongly associated with $\mathrm{RRD}^{1,4}$ due to the fact that myopic individuals, particularly those with high myopia, are more likely to have a thinner retina ${ }^{5}$ and are prone to experience premature vitreous liquefactions causing 

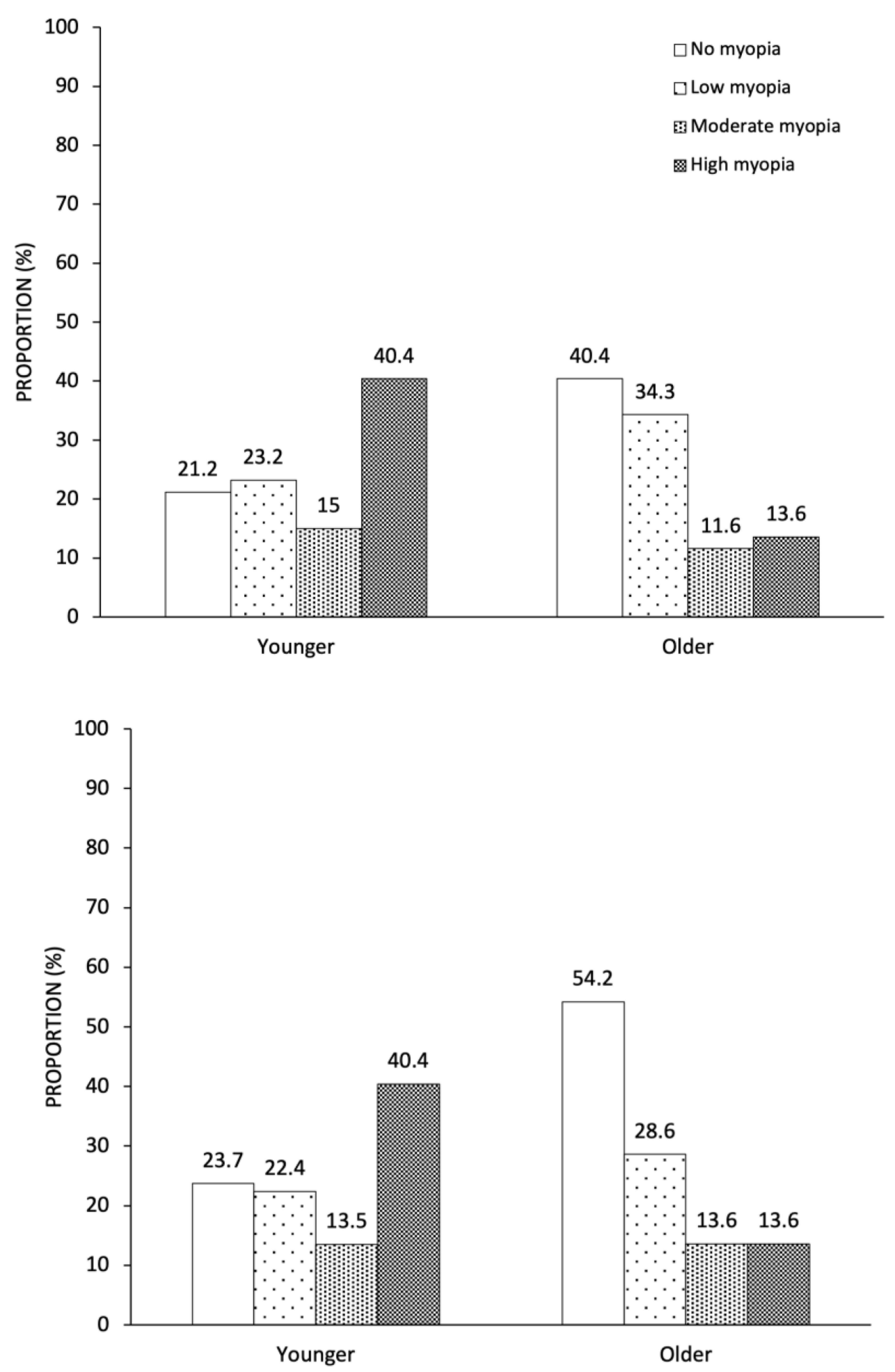

Figure 2 Proportion of refractive status in younger and older adults (Upper: overall; lower: phakic individuals).

posterior vitreous detachment. ${ }^{6}$ Taken together, those factors are key for the development of retinal tear and subsequent RRD. $^{7}$
Our results should be interpreted cautiously, mainly due to some information biases related to the retrospective design used in this study. The measurement of refractive 
error was based on previous glasses prescription of the affected eye. This was not the ideal assessment of refractive error; however, in the instance of RRD, measurement of refractive error using autorefractometer or partial coherence laser interferometry would have given inaccurate results. To minimize this bias, we matched patient's glasses prescription with the axial length measurement from a scan ultrasonography of the affected eye and measurement of refractive error of the fellow eye. Sensible values of those abovementioned measurements ensured that minimal bias was present.

In conclusion, younger individuals with RRD were more myopic than older ones in this study population. This finding strengthened the causality theory between myopia and RRD and supported previous observations that relate myopia and incident RRD. More importantly, this study also added to the existing literature that myopia could be more important risk factors of RRD in younger, but not in older individuals.

\section{Human and Animal Rights}

All procedures performed in studies involving human participants were in accordance with the ethical standards of the institutional and/or national research committee and with the 1975 Helsinki Declaration and its later amendments or comparable ethical standards.

\section{Ethics Approval and Consent to Participate}

Approval was obtained from the Medical and Health Research Ethics Committee, Universitas Gadjah Mada.
Medical record data de-identification was performed to ensure patients' anonymity.

\section{Disclosure}

The authors declare that they have no conflicts of interest in this work.

\section{References}

1. van Leeuwen R, Haarman AE, Van De Put MA, Klaver CC, Los LI; Group DRRDS. Association of rhegmatogenous retinal detachment incidence with myopia prevalence in the Netherlands. JAMA Ophthalmol. 2021;139(1):85-92. doi:10.1001/jamaophthal mol.2020.5114

2. Cheung N, Lee SY, Wong TY. Will the myopia epidemic lead to a retinal detachment epidemic in the future? JAMA Ophthalmol. 2021;139(1):93-94. doi:10.1001/jamaophthalmol.2020.5112

3. Kim MS, Park SJ, Park KH, Woo SJ. Different mechanistic association of myopia with rhegmatogenous retinal detachment between young and elderly patients. Biomed Res Int. 2019;2019:1-6. doi:10.1155/ 2019/5357241

4. Mitry D, Charteris DG, Fleck BW, Campbell H, Singh J. The epidemiology of rhegmatogenous retinal detachment: geographical variation and clinical associations. $\mathrm{Br} J$ Ophthalmol. 2010;94(6):678-684. doi:10.1136/bjo.2009.157727

5. Ikuno Y. Overview of the complications of high myopia. Retina. 2017;37(12):2347-2351. doi:10.1097/IAE.0000000000001489

6. Akiba J. Prevalence of posterior vitreous detachment in high myopia. Ophthalmology. 1993;100(9):1384-1388. doi:10.1016/S01616420(93)31471-5

7. Girsang W, Sari DC, Srigutomo W, Gondhowiardjo TD, Sasongko MB. Concept and application of relaxing radial retinectomy for retinal detachment with advanced proliferative vitreo-retinopathy. Int J Retina Vitr. 2020;6(1):1-8. doi:10.1186/s40942-020-00251-y
Clinical Ophthalmology

\section{Publish your work in this journal}

Clinical Ophthalmology is an international, peer-reviewed journal covering all subspecialties within ophthalmology. Key topics include: Optometry; Visual science; Pharmacology and drug therapy in eye diseases; Basic Sciences; Primary and Secondary eye care; Patient Safety and Quality of Care Improvements. This journal is indexed on PubMed

\section{Dovepress}

Central and CAS, and is the official journal of The Society of Clinical Ophthalmology (SCO). The manuscript management system is completely online and includes a very quick and fair peer-review system, which is all easy to use. Visit http://www.dovepress.com/ testimonials.php to read real quotes from published authors. 